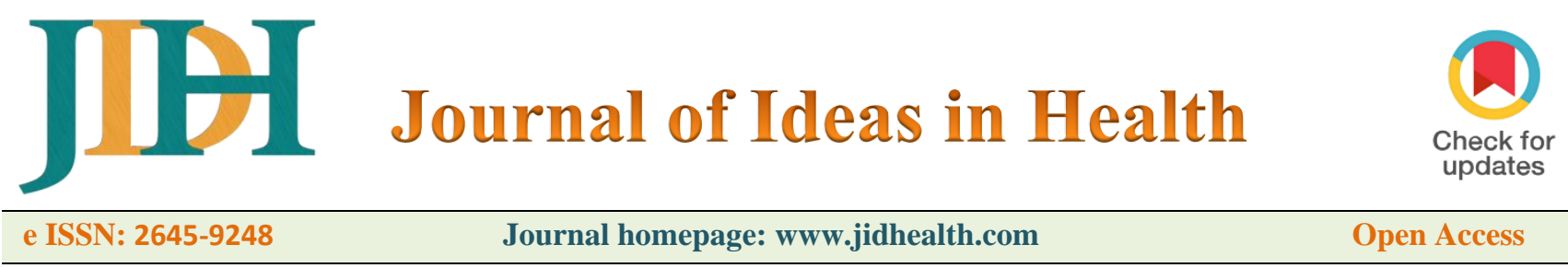

Original Article

\title{
Concerns and confidences expressed by teaching staff about the shift of medical education to online mode in South India during the COVID 19
} pandemic

\author{
Aboobacker Mohammed Rafi ${ }^{*}$, Pulikkottil Raphael Varghese ${ }^{2}$, Praveenlal Kuttichira ${ }^{3}$
}

\begin{abstract}
Background: Online education is prevalent in the country since the beginning of the 21st century. The outbreak of COVID-19, the government declared lockdown, and subsequent closing of institutions was unexpected, and it forced medical colleges to launch online programs for undergraduate courses. Due to the sudden shifting to online mode, most teaching staff members face the challenges of lacking online teaching experience, early preparation, or support from educational technology teams. This institution was in touch with the teachers and students through online mode, enquiring about their welfare and wellness. The present study focuses on concerns and confidences presented by the medical teaching staff on online medical education.
\end{abstract}

Methods: This study was conducted at Jubilee Mission Medical College \& Research Institute, a medical college in central Kerala in south India. This institution conducted online classes for undergraduate (UG) medical students through Google classroom and YouTube platforms. There was 186 teaching staff from 21 departments involved in undergraduate (MBBS) teaching in this Institute. In this study, we collected information from the teaching staff about the online classes that they handled. A 27-point survey form was designed using a Google survey and mailed to them. The responses were collected in a week. The data collected was analyzed.

Results: Fifty-one members responded. All responding teachers preferred regular classroom teaching due to the provision for better teacher-student interaction. However, one-third of respondents wanted the continuation of online classes, even after resuming classroom teaching. Out of 51 responses, 24 teachers graded the success of the programs more than $90 \%$. The major suggestions received for further improvement of the program were that the departments provided their hardware and software, centralized online sessions for practical purposes, and collected regular feedback from students.

Conclusion: The successes of our online teaching programs were limited to didactic teaching only. It could not replace the actual patient examination in a clinical setting, which involves communication skills and emotional relationships. This adversary must be converted into an opportunity to develop e-learning programs. This pandemic should open our eyes, so we learn from it and be better prepared for the future.

Keywords: COVID 19, Pandemic, Teaching Staff, Concerns, Online Medical Education, Kerala, India

\section{Background}

COVID 19 pandemic affected medical education worldwide and is likely to leave lasting changes [1]. Technologically novel methods of teaching have ensured the continuation of medical education during pandemic times [2]. Governments were forced to close down education institutions even in the midst of examinations but had to continue the courses, especially those

*Correspondence: amrafi02@gmail.com.

${ }^{1}$ Department of Transfusion Medicine \& Clinical Lab, Jubilee Mission Medical College and Research Institute, India.

Full list of author information is available at the end of the article related to health care. Distance education was the only possible mode, but most countries were inexperienced and unprepared [3]. Colleges had to develop their mechanism to conduct online teaching programs. COVID-19 pandemic is expected to have a positive impact, especially in improving the acceptance of online education. The teachers' support is of utmost importance, especially in the institutions for such a transition. In a study conducted in Saudi Arabia on online medical education, most of the teachers supported it. Many of the faculties were satisfied with online teaching despite using teaching methods that were new to them. Some of them even stated that the COVID-19 pandemic proved the efficacy of online education. The teachers 
reported reaching out to their other colleagues, administrators, librarians, and information technology (IT) personnel to assist in the transition to online education. The teachers also reported the need to re-examine their prevailing teaching practices [4]. Our institution continued to remain in contact with students during this unexpected closedown of the medical college. This was through social media, keeping in touch with the wellbeing of them and their families. Their involvement in the seven-point program announced by India's Government during the first extension of lockdown was also inquired [5]. Students reported interest in the continuation of classes through online mode, accessible to everyone, though a few had temporary hitches [6]. There were initiatives at different medical schools all over the world to switch over to online mode. The involvement and response from teaching staff were equally important to the student response. The documentation and analysis of current efforts and changes will contribute to medical education advancement [7]. This publication aimed to report the experience of our teaching staff in undergraduate online medical teaching.

\section{Methods}

This study was conducted at Jubilee Mission Medical College \& Research Institute, a medical college in central Kerala in south India. It offers both undergraduate (MBBS) and postgraduate (MD/MS /DM) programs. It was decided to impart online classes to undergraduate students on the government's closure by the government owing to the COVID 19 pandemic. The online platforms used for taking classes in the college were not uniform. Various departments and teachers used various platforms. Most teachers used either google classroom or recorded YouTube videos. The department of physiology used the "Impartus platform". The study period was for a week from 19th to 25th June 2020. Since individual identity is not disclosed, participation was not mandatory. Patient doctor relationship was not involved as the study involved the didactics only.

\section{Study questionnaire}

A pre-structured questionnaire was formed using Google Forms and was circulated through email and on social media platforms like WhatsApp. A 27-point survey form was designed. (Box1). The questions were mainly multiple-choice questions to select at least one answer. There was an option to write down; if it was none of the given: The Google survey quantified the survey responses, and results were analyzed, interpreted, and presented.

\section{Statistical analysis}

Qualitative data were expressed as proportions and quantitative data as mean (M) and Standard Deviation (SD) or Median and IQR depending on the distribution.

\section{Results}

There were 186 teaching staff from 21 departments involved in MBBS teaching in this Institute. A total of 51 teachers responded to the survey. Among them, 10 were Heads of Departments, 8 were Professors, 11 were Associate Professors, 14 were Assistant Professors, and 8 were Senior Residents. These teachers altogether had taken classes for 405 hrs. Google classroom and YouTube were the widely used platforms, and most teachers selected Google classroom because of higher teacher friendliness. However, only one teacher reported the experience of using more than one platform. Since most of them were using only one platform, they were unable to select the best one. All responding teachers preferred regular classroom teaching due to the provision for better teacher-student interaction. The timetable was pre-circulated by $90 \%$ of respondents, and attendance of participation was recorded based on the submission of assignments. Sixty percent reported that they could cover more than $90 \%$ of the necessary portion. One teacher reported that classes taken were only less than $50 \%$ of the portion specified to be covered during that period. One-third of respondents wanted the continuation of online classes, even after resuming classroom teaching. Nine of them felt the need to repeat the already done classes once the regular classes resume. Ten of the respondents were ready to try out online teaching programs for practical sessions also. Seventy percent of faculties were ready to share classes for later use, and $35 \%$ preferred centralized classes by University (Table 1). The overall response was that regular classroom teaching is better since it enables interaction with students.

Out of 51 responses, 24 teachers graded the success of the programs more than $90 \%$. Twenty-two members graded between $71 \%$ and $90 \%$. Sixteen percent of teachers reported students would rate their classes with more than $90 \%$ (Table 2). The major suggestions received for further improvement of the program were that the departments provided their hardware and software, centralized online sessions for practical and collecting regular feedback from students.

\section{Box 1 Contents of the questionnaire to teaching staff}

\section{Details of Teacher}

Name of teacher, Designation, Departmen

Details from Head of Department

Department email id, Number of teacher,

Number of teachers engaging in online classes?

\section{Teacher statements}

The number of Classes / Hours taken?

The main hindrance you face in online mode

Which internet facility is being used, Which Gadget is being used?

Which online method is being used?

Is the Timetable shared beforehand?

How was attendance noted in the online classes?

\section{Teacher suggestions}

Preference for classroom teaching or online platforms? Why?

Which all platforms have been used by you? (Multiple answers)

Most and least teacher-friendly online platform?

Are you willing to continue online classes after regular classes start? Whether repetition of online classes is needed once usual classes start?

Would you like to take practical sessions also online?

Would you like to share the online sessions with students for later use?

Would you prefer centralized online classes conducted by the University?

Any suggestions/Remarks?

\section{Self-appraisal (out of 100)}

Grade your department for the completion of the syllabus during Lockdown

Grade your department for overall Performance in Online classes Your opinion about 'students rating' regarding your online classes? 
Table 1 Response from the teaching staff $(n=51)$

\begin{tabular}{|c|c|c|c|c|c|}
\hline No & Questions & & esponses & & No Reply \\
\hline 1 & Hindrance faced & Nil 29 & Technical 22 & - & 0 \\
\hline 2 & Internet facility & Department 31 & Own 16 & - & 4 \\
\hline 3 & Type of gadget & Desktop 29 & Laptop 13 & Tablet 9 & - \\
\hline 4 & Online method & Recorded 45 & Live 2 & - & 4 \\
\hline 5 & Like to continue after regular classes resume & Yes 17 & - & - & 34 \\
\hline 6 & Repetition after regular classes resume & Yes 9 & - & - & 42 \\
\hline 7 & Timetable shared & Before 46 & - & - & 5 \\
\hline 8 & Attendance noted on & Submission 46 & - & - & 5 \\
\hline 9 & Share the online sessions with students for later use & Willing 36 & - & - & 15 \\
\hline 10 & Centralized online classes by University & Favor 18 & - & - & 33 \\
\hline
\end{tabular}

\section{Discussion}

The novel coronavirus has transformed the world in the blink of an eye, including medical education. During the period of lockdown, hand washing, and tracking the global spread, there has been a huge surge in search phrases like "how to teach online", "best online teaching platforms", "online teaching tools", and "online teaching techniques". Even proficient teachers had to do a re-learning to be a teacher in online platforms [8]. In the present study, google classroom and YouTube were the widely used platforms. Some institutes are using video conference tools like Zoom and Microsoft Teams to deliver live lectures. Some institutes instruct their teaching staff to record their lectures using a screen recorder. These recordings are shared through WhatsApp groups or closed Facebook groups [9]. Besides selecting the platform and familiarizing with its entire features, classroom management is also posing a challenge. Attracting attention, maintaining discipline, clearing doubts, gathering instant feedbacks, assessing effectiveness, etc., are encountered [8]. The right hardware and adequate internet connectivity also matter. In this study majority of the teachers were using videos for the teaching. These may vary at different institutions [9]. However, the differences in levels exist between colleges even before online teachings started. Marking attendance is also a challenge, and there are concerns that the students may mark proxy attendance while engaging in other online activities at the same time. In the present study, $90 \%$ of the teachers recorded attendance on successful submission of assignments. Formal training for teachers is a necessity for conducting online assessments. Student engagements must be promoted, and interaction must be verified by incorporating quizzes and mini assignments [9]. Training in online mode may not affect Preclinical and Para clinical subjects but will negatively affect the clinical subjects [8]. The success of online teaching programs is limited to didactic teaching, as many opined. It cannot replace the actual patient examination in a clinical setting which cover communication skills and emotional relationship [10]. A shift to online teaching, reduced face to face contacts, and transformation of the examination system are happening while the pandemic is continuing for a long duration [11]. Technology-driven computerized laboratories and simulation labs have already started replacing traditional teaching methods in medical sciences. However, history taking, clinical examination, gathering information from case records, and communicating with patients and other caregiving stakeholders are important, which cannot be done without real patient and real time supervision. $\underline{\text { Table } 2 \text { Self grading of online classes }(\mathrm{n}=51)}$

\begin{tabular}{lll}
\hline $\begin{array}{l}\text { Percentage of } \\
\text { success rate }\end{array}$ & $\begin{array}{l}\text { Self-rating by } \\
\text { teacher }\end{array}$ & $\begin{array}{l}\text { Expected rating } \\
\text { by students }\end{array}$ \\
\hline $90 \%$ or more & 24 & 8 \\
$71 \%$ to $90 \%$ & 22 & 24 \\
$51 \%$ to $70 \%$ & 3 & 9 \\
Below 50\% & 0 & 1 \\
Do not know & 2 & 9 \\
Total Responses & 51 & 51 \\
\hline
\end{tabular}

While COVID 19 has created challenges, identifying these challenges, and converting them into opportunities is the best and only choice for the medical teaching staff [4]. Only onethird of teachers wanted to continue online classes even after resuming classroom teaching. In another study, most of the respondents preferred combining online with face-to-face instruction. This shows that a hybrid learning system is becoming more accepted among academic communities because it combines "the best of both worlds" [12]. However, the effectiveness of hybrid learning depends on several factors, mainly adequate teaching staff training and institutional support [13]. Whatever may be the future of this system, many teachers in this study expect that the success rate of this program is $90.0 \%$ and above. Many of them anticipate that the students will also grade them above $90.0 \%$. The entry of new doctors at the end of every academic year is an essential requirement, but the standards should not fall [14]. In countries like Brazil, there was support for medical institutions for continuing the teaching programs [1]. However, such things did not happen in India despite there being universities and councils that oversee medical education. Nevertheless, medical colleges continued the teaching programs using online platforms, and clinical works continued without a break. The prolonged educational lockdown period has brought many challenges to the teachers at various medical colleges in providing quality education to their students [9]. The expectance of returning everything to normal soon, anguish for the lost period and lack of developed skill, negotiating for using time, depression on seeing deaths around, and finally accepting reality and starting online classes are understandable emotional responses [15]. Parents, teachers, and administrators' partnership is needed to reach a new equilibrium and a new normal [8].

\section{Conclusion}

In the present study, most of the responding teachers preferred regular classroom teaching due to better teacher-student interaction. However, a good number of teachers favored the hybrid teaching process. The respondents gave suggestions for 
further improvement of the program. Institutions providing their hardware and software, centralized online sessions for practical, and collecting regular feedback from students were the major suggestions. The Medical Council of India \& other health universities that oversee medical education should rise to the situation and bring in innovations so that future health care workers are not deprived of both theoretical \& practical knowledge.

\section{Abbreviation}

COVID-19: Coronavirus Disease-19; IT: Information Technology; MBBS: Bachelor of Medicine and Bachelor of Surgery; JMMCRI: Jubilee Mission Medical College and Research Institute, Thrissur; UG: undergraduate

\section{Declaration}

acknowledgment

The authors thank Ms. Limmy Antony for all the secretarial support, including mailing the inquiries, survey, and receiving the responses.

\section{Funding}

The authors received no financial support for their research, authorship, and/or publication of this article.

Availability of data and materials

Data will be available by emailing amrafi02@gmail.com.

\section{Authors' contributions}

Aboobacker Mohammed Rafi (AMR), Pulikkottil Raphael Varghese (PRV), and Praveenlal Kuttichira (PK) are equally participated in the concept, design, writing, reviewing, editing, and approving the manuscript in its final form. All authors have read and approved the final manuscript.

Ethics approval and consent to participate

We conducted the research following the Declaration of Helsinki, and the protocol was approved by the Jubilee Mission Medical College and Research Institute, India -2020.

Consent for publication

Not applicable

Competing interest

The author declares that they have no competing interests.

Open Access

This article is distributed under the terms of the Creative Commons $\begin{array}{llll}\text { Attribution } & 4.0 & \text { International License }\end{array}$ (http://creativecommons.org/licenses/by/4.0/), which permits unrestricted use, distribution, and reproduction in any medium, provided you give appropriate credit to the original author(s) and the source, provide a link to the Creative Commons license, and indicate if changes were made. The Creative Commons Public Domain Dedication waiver (http://creativecommons.org/publicdomain/zero/1.0/) applies to the data made available in this article, unless otherwise stated.

Author details

${ }^{1}$ Department of Transfusion Medicine \& Clinical Lab, Jubilee Mission Medical College and Research Institute, India. ${ }^{2}$ Jubilee Centre for Medical Research, Jubilee Mission Medical College and Research Institute, India. ${ }^{3}$ Department of Psychiatry \& Principal, Jubilee Mission Medical College and Research Institute, India.
Article Info

Received: 16 October 2020

Accepted: 17 December 2020

Published: 24 December 2020

\section{References}

1. Tempski P, Danila AH, Arantes-Costa FM, Siqueira MA, Torsani MB, Martins MA et al. The COVID-19 pandemic: time for medical teachers and students to overcome grief. Clinics. 2020;75. http://dx.doi.org/10.6061/clinics/2020/e2206

2. Kay D, Pasarica M. Using technology to increase student (and faculty satisfaction with) engagement in medical education. Advances in physiology education. 2019 Sep 1;43(3):408-13. https://doi.org/10.1152/advan.00033.2019

3. Bentata Y. COVID 2019 pandemic: a true digital revolution and birth of a new educational era, or an ephemeral phenomenon? Medical education online. 2020;25(1). https://dx.doi.org/10.1080\%2F10872981.2020.1781378

4. Rajab MH, Gazal AM, Alkattan K. Challenges to online medical education during the COVID-19 pandemic. Cureus. 2020 Jul;12(7). https://dx.doi.org/10.7759\%2Fcureus.8966

5. Rafi AM, Varghese PR, Kuttichira P. COVID 19 PandemicAffidavit by academic personnel on wellbeing and social responsibility from a Medical College in Central Kerala Volume: Journal of the Social Sciences July 2020 48(3). https://bit.ly/3ma7IWf

6. Rafi AM, Varghese PR, Kuttichira P. The pedagogical shift during COVID 19 pandemic: online medical education, barriers and perceptions in central Kerala. Journal of Medical Education and Curricular Development. 2020 Aug; 7:2382120520951795 https://doi.org/10.1177\%2F2382120520951795

7. Rose S. Medical student education in the time of COVID-19. Jama. 2020 Mar 31 https://doi.org/10.1001/jama.2020.5227

8. Ortiz PA. Teaching in the time of COVID-19. Biochemistry and molecular biology education. 2020 Apr 2. https://doi.org/ https://doi.org/10.1002/bmb.21348

9. Farooq F, Rathore FA, Mansoor SN. Challenges of online medical education in Pakistan during COVID-19 Pandemic. J Coll Physicians Surg Pak. 2020 Jun;30(6):67-69. https://doi.org/10.29271/jcpsp.2020.Supp1.S67.

10. Hammond D, Louca C, Leeves L, Rampes S. Undergraduate medical education and Covid-19: engaged but abstract. Medical Education Online. 2020 Jan 1; 25(1):1781379. https://doi.org/10.1080/10872981.2020.1781379

11. Feldman Embracing the future of learning and teaching. 2020. Available

from https://www.universitiesuk.ac.uk/blog/Pages/embracing-thefuture-learning-teaching.aspx.

12. Orleans, Myron, ed. Cases on Critical and Qualitative Perspectives in Online Higher Education. Hershey, PA: IGI Global, 2014. https://doi.org/10.4018/978-1-4666-5051-0

13. Comas-Quinn A. Learning to teach online or learning to become an online teacher: An exploration of teachers' experiences in a blended learning course. ReCALL.2011; 23(3): 218-232. https://doi.org/10.1017/S0958344011000152

14. Gillon R. Medical ethics: four principles plus attention to scope BMJ (Clinical research ed.).1994; 309(6948), 184-188. https://doi.org/10.1136/bmj.309.6948.184

15. Bhat R, Singh VK, Naik N, Kamath CR, Mulimani P, Kulkarni N et al. COVID 2019 outbreak: The disappointment in Indian teachers. Asian J Psychiatr. 2020 Apr; 50:102047. https://doi.org/10.1016/j.ajp.2020.102047 